\title{
Status index of optimal water variables for biodiversity conservation in the Lagoon of Sonso in Colombia
}

\author{
Gloria Yaneth Florez Yepes ${ }^{1}$, Alejandro Rincón Santamaría, ${ }^{1,2}$, Vladimir Henao Céspedes ${ }^{1}$, \\ Juan Carlos Granobles ${ }^{3}$, Fredy Edimer Hoyos $^{4}$ \\ ${ }^{1}$ Grupo de Investigación en Desarrollos Tecnológicos y Ambientales-GIDTA, Facultad de Ingeniería y Arquitectura, Universidad \\ Católica de Manizales, Manizales, Colombia \\ ${ }^{2}$ Grupo de Investigación en Microbiología y Biotecnología Agroindustrial-GIMIBAG, Facultad de Ciencias de la Salud, Universidad \\ Católica de Manizales, Manizales, Colombia \\ ${ }^{3}$ Centro de investigación en Medio Ambiente y Desarrollo de la Universidad de Manizales, Manizales, Colombia \\ ${ }^{4}$ Departamento de Energía Eléctrica y Automática, Facultad de Minas, Universidad Nacional de Colombia, Medellín, Colombia
}

\begin{tabular}{|c|c|}
\hline Article Info & ABSTRACT \\
\hline Article history: & In order to determine an index of the status of optimal water variables for \\
\hline Received Mar 5, 2021 & biodiversity conservation in the Sonso Lagoon, the data obtained from 2004 \\
\hline Revised Jul 15, 2021 & $\begin{array}{l}\text { to } 2018 \text { were used. To determine the index, a methodology based on a } \\
\text { multivariate analysis of the physical-chemical water variables was used, as }\end{array}$ \\
\hline Accepted Aug 4, 2021 & $\begin{array}{l}\text { well as a correlation analysis for their delimitation. Subsequently, the } \\
\text { definition of weights and the parameterization of the variables for the final }\end{array}$ \\
\hline Keywords: & $\begin{array}{l}\text { construction of the index were made. As a result, it was found that the } \\
\text { lagoon is in an adequate state with a value index of } 0.65 \text {, with a highly }\end{array}$ \\
\hline Index of conservation & $\begin{array}{l}\text { vulnerable tendency to be in an acceptable state and go to a critical state, } \\
\text { depending on the anthropic pressure it has. As a conclusion it was obtained }\end{array}$ \\
\hline Lagoon of sonso & that variables such as dissolved oxygen, total phosphorus and electrical \\
\hline $\begin{array}{l}\text { Water quality } \\
\text { Wetlands }\end{array}$ & conductivity are determining factors in establishing the index. \\
\hline
\end{tabular}

This is an open access article under the CC BY-SA license.

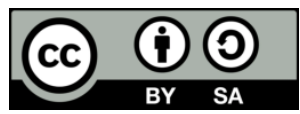

\section{Corresponding Author:}

Gloria Yaneth Florez Yepes

Ingeniería Ambiental, Facultad de Ingeniería y Arquitectura, Universidad Católica de Manizales

Manizales-Colombia, Cra 23 No. 60-63, Colombia

Email: gyflorez@ucm.edu.co

\section{INTRODUCTION}

There are different methodologies to assess the degradation of aquatic systems, on the one hand, some focused on the biotic component, using organisms as biological indicators and are more developed in Europe, USA and somewhat less in Latin America [1]. On the other hand, there are the indices referring to the abiotic components, which directly evaluate the physical and chemical quality of the water, and a third element that evaluates the habitat conditions to sustain the biota, such as the indices of habitat quality and bank structure, separated or gathered in river quality índices [2], [3]. This paper will specifically address quality indices, which according to [4], [5] water resource quality in wetlands is being increasingly accelerated by anthropogenic factors that cause physico-chemical conditions such as biologycal oxygen demand (BOD), $\mathrm{pH}$ and others to be significantly affected. Some of the quality indicators that have been considered are organic matter load, dissolved oxygen, and nutrient concentration, among others. Several recent studies [6], [7] uses the variables oxygen demand (OD), temperature, coliforms, $\mathrm{pH}$, suspended solids (SS), turbidity, transparency, nitrates, phosphates, fats, color and odor, through which the organoleptic characteristics, effect on aquatic life and human health can be evaluated from the source. Also, in the work of [8] an expert evaluation of selection of important variables for water quality was carried out and it was concluded that those of greater importance were: OD, fecal coliforms, $\mathrm{pH}$, BOD5, secchi disk transparency 
(SDT), NO3-N, phosphates, temperature and turbidity. The selection of the indicator variables to construct the index of state of conservation in the present study, depended, not only on the cited literature, but also on the concept of experts and the economic availability to develop it. For this analysis, the water parameters considered were based on [9], who propose that the previous parameters and especially the temperature and the dissolved oxygen are determining factors for vital processes in organisms, as well as as proposed [10][12], where the design of a system for analysis of water quality in wetlands is carried out.

\section{METHOD}

The area of study corresponds to the Sonso Lagoon located in the department of Valle del Cauca, in Colombia, is a natural ecosystem of 14 square kilometers. With physicochemical data of the lagoon's water, an index of its state of conservation was determined, for which the following procedure was carried out: the data corresponds to a period from 2004 to 2017, the variables initially available were a total of 57, of which, based on multivariate and principal component analysis, 13 were prioritized, with which the wetland quality index, multivariate and correlation analysis was established. Likewise, a cluster analysis was carried out in order to determine the groupings of the variables studied with the SPADN V.5.6 software (portable system for the analysis of numerical data) and later a factorial and community analysis was carried out in the SAS software (statistical analysis system 8.0). The communality refers to a common variance or covariance, which expresses the proportion of the total variance of such variable, which is shared with the other P-1 remaining observed variables, with this the weights of the prioritized variables were determined, likewise the representativeness of the components above 80 was taken. Afterwards, a data standardization process was carried out where a support table was initially elaborated to compare the behavior of the variables with reference to the quality level, which served to support the standardization process as shown in Table 1 . Below is the supporting table, where the related data was obtained from the literature review as the optimal parameters for wildlife conservation in a wetland.

Table 1. List of the optimal data consulted for the parameters studied

\begin{tabular}{|c|c|c|c|c|c|}
\hline \multirow{2}{*}{ Variable } & \multirow{2}{*}{ Units } & \multicolumn{2}{|c|}{ Ranges consulted } & \multirow[t]{2}{*}{ Assessment Criteria } & \multirow{2}{*}{ Source } \\
\hline & & Min & Max & & \\
\hline OD (Dissolved oxygen) & $\mathrm{Mg} / \mathrm{L}$ & 5 & 10 & The more the better & $\begin{array}{c}\text { Ministry of Agriculture, } 1984 \text { Decree } 1594 \\
\text { of } 1984 .\end{array}$ \\
\hline TB (turbidity) & NTU & 0 & 100 & The more, the worse & {$[8]$} \\
\hline $\mathrm{Ca}$ & $\mathrm{Ca}$ & & $100 \mathrm{ppm}$ & & [13] \\
\hline Temperature & & 24.4 & 30 & & [14] \\
\hline
\end{tabular}

Normalization of each variable: using the methodology of [15] it was proceeded to normalization where a range of 0 to 1 was considered, the closer to 0 the situation is less favorable, the closer to 1 the situation is more favorable. The attributes of the previous author pose: ("more is better", "more is worse" or "optimal range"), on each attribute an application formula was considered for the standardization process. In order to determine the function of belonging, the literature and expert consultation were used to determine which function to apply for each variable, in reference to more is better, more is worse or if it is within the range. The formulas applied according to [15], were the following:

$$
\begin{aligned}
& + \text { the better }=\frac{(\text { Vo }-V \min )}{(V \max -V \min )} \\
& + \text { the worse }=\frac{(\text { Vo }-V \max )}{(\text { Vmin }-V \max )}
\end{aligned}
$$

where $V o$ is the calculated value of the variable; Vmin is the minimum value of the variable; Vmax is the maximum value of the variable; $L_{\text {inf }}$ is the lower limit of the optimal range; $L_{\text {sup }}$ is the upper limit of the optimal range. The formula corresponding to 'more is better' case is used when the variable is positive, whereas the formula corresponding to 'more is worse' case is used when the variable is negative. The normalized value ranges between 0 and 1 , where 1 is obtained for the optimal value of the variable. Finally, we proceeded to establish an interpretation scale for the index which was adapted taking as reference the [16]. The following formula was used to define the total index: 


$$
C S I=\sum V i(X i) \times W
$$

where $C S I$ is the conservation status index; $V i(X i)$ is a value function of the environmental quality of each variable $\mathrm{i}$, which depends on its indicator $X$; and $W$ is a relative weight given to each variable $i$.

\section{RESULTS}

Once the correlation coefficient analysis for main components was performed, the results of the component analysis are shown in Table 2, and in Table 3 the participation of physical-chemical variables in selected major components is shown, it was found that there is a high correlation between calcium and magnesium; electrical conductivity and total solids; alkalinity with total hardness; total hardness and total solids; calcium hardness and electrical conductivity; magnesium hardness and total solids; magnesium hardness with electrical conductivity; magnesium hardness with total solids; magnesium versus electrical conductivity and magnesium with total solids, alkalinity with bicarbonate; calcium hardness with total hardness and magnesium hardness with total hardness, calcium and magnesium with total hardness. The following were removed from the previous ratio analysis: magnesium hardness, calcium hardness, magnesium, bicarbonate, total hardness, total solids and alkalinity. The first five components were selected for a total explained variability of $74.32 \%$.

Table 2. Analysis of main components of physical-chemical parameters

\begin{tabular}{cccc} 
of the water of the Sonso Lagoon, but & 2009-2018 \\
\hline Components & Eigenvalue & Proportion & Cumulative \\
\hline 1 & 3.02621109 & 0.2328 & 0.2328 \\
2 & 2.62979853 & 0.2023 & 0.4351 \\
3 & 1.75006658 & 0.1346 & 0.5697 \\
4 & 1.26466488 & 0.0973 & 0.6670 \\
5 & 0.99111702 & 0.0762 & 0.7432 \\
6 & 0.88965199 & 0.0684 & 0.8117 \\
7 & 0.69145711 & 0.0532 & 0.8648 \\
8 & 0.64797421 & 0.0498 & 0.9147 \\
9 & 0.44864158 & 0.0345 & 0.9492 \\
10 & 0.28301495 & 0.0218 & 0.9710 \\
11 & 0.19474426 & 0.0150 & 0.9859 \\
12 & 0.15147951 & 0.0117 & 0.9976 \\
13 & 0.03117828 & 0.0024 & 1.0000 \\
\hline
\end{tabular}

Table 3. Participation of physical-chemical variables in selected major components

\begin{tabular}{cccccc}
\hline Physical-Chemical Variables & Prin1 & Prin2 & Prin3 & Prin4 & Prin5 \\
\hline Room temperature & -0.208030 & 0.080093 & 0.067175 & 0.589034 & 0.279281 \\
pH & -0.472683 & 0.225790 & 0.110314 & -0.086099 & 0.055623 \\
CE & 0.508797 & 0.146475 & -0.078525 & 0.213177 & 0.120779 \\
Turbidity & -0.076561 & -0.133148 & 0.320020 & 0.080149 & 0.757846 \\
DBO & 0.129849 & 0.229293 & 0.487533 & 0.036235 & -0.189507 \\
DQO & 0.161552 & 0.084022 & 0.604872 & 0.094021 & -0.067123 \\
OD & -0.273000 & -0.304305 & -0.352233 & 0.158286 & 0.136696 \\
Ca & 0.499679 & -0.209866 & -0.078705 & 0.241846 & 0.077915 \\
Nitamon & 0.257795 & 0.349012 & -0.263054 & -0.115307 & 0.104695 \\
NNO3 & -0.141632 & 0.026688 & -0.018800 & 0.641727 & -0.452337 \\
NNO2 & -0.011952 & 0.316636 & -0.177128 & 0.268774 & 0.066504 \\
Phosphates & 0.101980 & 0.530937 & -0.172563 & 0.029124 & 0.135787 \\
Total phosphates & 0.065805 & 0.449964 & -0.101070 & 0.043168 & 0.162437 \\
\hline
\end{tabular}

\subsection{Presence of bases in the water}

It is made up of the electrical conductivity, the calcium concentration $\left(\mathrm{Ca}^{+2}\right)$ and the $\mathrm{pH}$, which represent a variability of $23.28 \%$. The electrical conductivity (EC), is a physical parameter of water, which is related to chemical parameters such as ion concentration $\left(\mathrm{Ca}^{+2}, \mathrm{H}^{+}\right)$and $\mathrm{pH}$. Considering the above, there is a linear relationship between calcium concentration and electrical conductivity, as stated [17]. Calcium and $\mathrm{pH}$ in north and central Swedish mire waters. That is, the higher the concentration of calcium, the higher the conductivity of the water solution, which is related to water hardness. On the other hand, the $\mathrm{pH}$ being a measurement of free ions in the water of Hydrogen, presents a linear relation with the EC, since as it was explained previously, EC is related to the concentration of ions (such as calcium, hydrogen, among others). 


\subsection{Phosphorus content in water}

It is made up of phosphates and total phosphorus, which corresponds to a variability of $20.23 \%$. According to [18] the excess of total phosphorus in water generates eutrophication, its measurement includes different compounds such as orthophosphates, polyphosphates and organic phosphorus.

\subsection{Oxygen demands (BOD and COD)}

Corresponds to both biological and chemical oxygen demands with a variability of $13.46 \%$. According to [19] biologycal oxygen demand (BOD) and chemical oxygen demand (COD), are related since both indicate the importance of discharges into wastewater and their possibility of biodegradation, however, it is important to note that according to the literature temperature also has a high relationship with these two indicators, however, in this analysis no such relationship is shown.

\subsection{Nitrate content}

It is formed by temperature and Nitrogen in the form of Nitrates that corresponds to a variability of $9.73 \%$. According to [20] temperature has a high elation with nitrates, in the sense that when there are high temperatures there is a greater process of decomposition of organic matter found in water and soil which is converted into amino acids, then ammonium, then nitrites and finally nitrates.

\subsection{Turbidity}

This component is represented by the turbidity which represents a variability of $6.84 \%$. "Turbidity is of great health importance, since it reflects an approximation of the content of colloidal, mineral or organic matter, and therefore may indicate contamination" [21]. In accordance with the above, Figure 1 shows how the variables are grouped against the composition of variables for each of the first five main components. The composition of variables per component shows the most related variables within each of them, presenting a greater relationship between phosphorus contents and chemical and biochemical demands of oxygen, these components are contrary to the components formed by variables such as ambient temperature, nitrogen as nitrates and water turbidity. The EC and the concentration of $\mathrm{Ca}$ form a component that is diametrically opposed to the others.

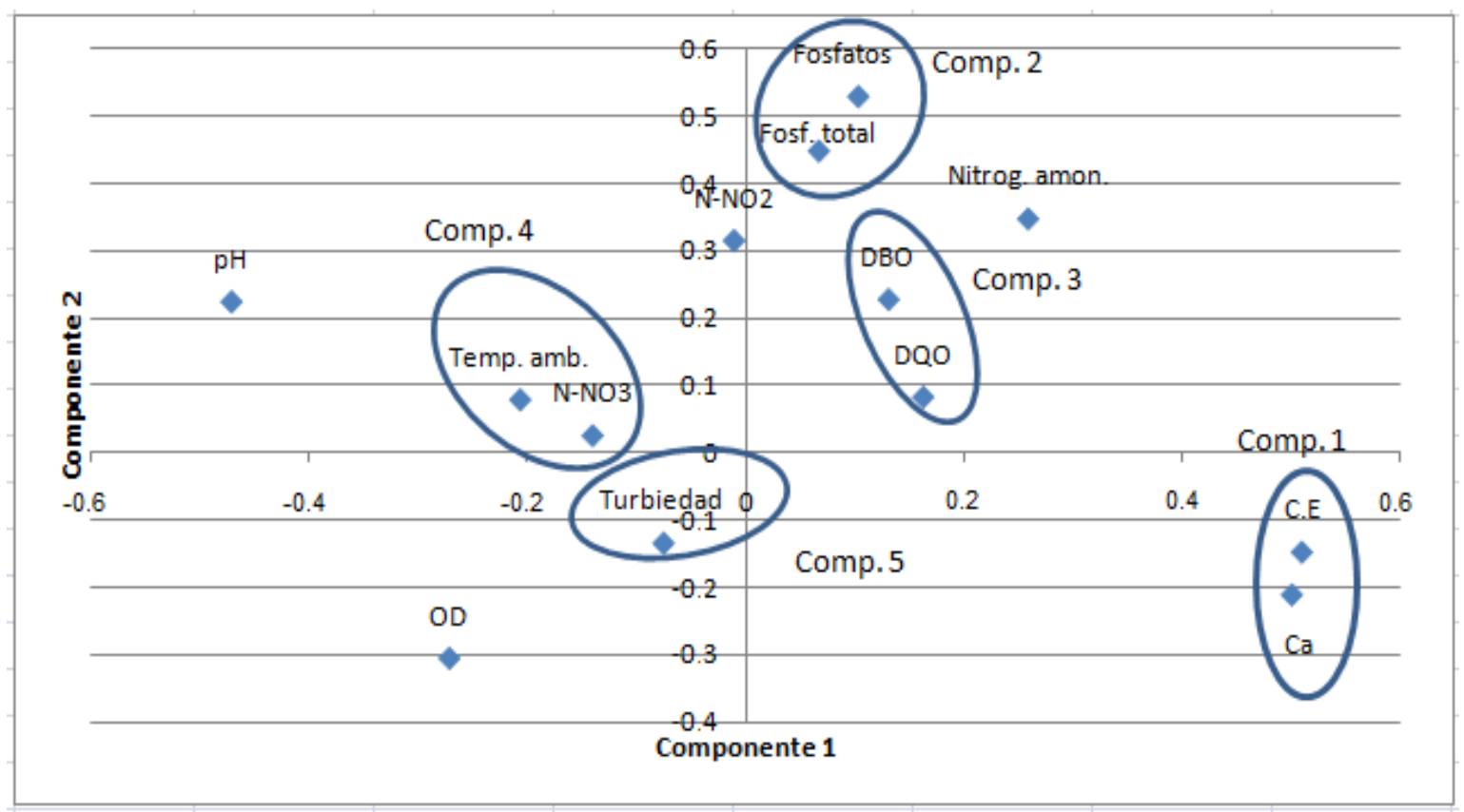

Figure 1. Composition of variables for each of the first five main components. Water quality, Sonso Lagoon, Valle del Cauca

\subsection{Standardization of parameters}

With the formulas (1), (2) and (3) [15] and based on the consulted data of the optimal degrees of each parameter the following standardization was obtained as shown in Table 4. 
Table 4. List of optimal parameter levels for standardization

\begin{tabular}{cccccc}
\hline \multirow{2}{*}{ Variable } & \multirow{2}{*}{ Tendence } & \multicolumn{2}{c}{ Consulted Data } & \multicolumn{2}{c}{ Observed } \\
& & Min & Max & Mín_Observ & Max_observ \\
\hline OD & + IS BETTER & 5 & 10 & 6.375 & 7.63 \\
pH_A & OPTIMAL RANGE & 6 & 8.5 & 6.423 & 7.718 \\
TB & + IS WORSE & 0 & 100 & 1.473 & 20.113 \\
T & OPTIMAL RANGE & 24.4 & 30 & 18 & 34 \\
CE & + IS WORSE & 60 & 2000 & 60 & 2954 \\
NNO & + IS WORSE & 0 & 11.24 & 0.007 & 3.049 \\
NNO2 & + IS WORSE & 0 & 0.03 & 0.003 & 0.86 \\
Phosphates & + IS WORSE & 0 & 0.5 & 0 & 3.95 \\
Total phosphorus & + IS WORSE & 1 & 51 & 0.03 & 5.94 \\
\hline
\end{tabular}

\subsection{Determination of weights}

Weights were determined from the S.A.S. software by the communal method where the following results were obtained as shown in Table 5. The percentage column corresponds to the weight that was given to each of the variables to proceed to determine the total index, as can be seen in the table, the one that obtained the highest percentage was phosphate, total phosphorus and dissolved oxygen, as initially mentioned dissolved oxygen has been a fundamental variable for the conservation of wildlife according to [9], as well as total phosphates and phosphors have been determinant in the processes of eutrophication of wetlands [14], therefore it is consistent that these variables have the highest weights, higher values in weights. With the determination of weights, the procedure was to generate the total index, which is shown in Figure 2.

The most optimal parameters obtained were those related to $\mathrm{pH}$, temperature and total phosphorus, the latter being one of the most important for the standardization process. Dissolved oxygen, being one of the most important for the study of wetlands, was the one that obtained the lowest index. The adapted parameterization of Table 6 of [16]. Table 6 allows us to establish that the Sonso Lagoon having a quality index for the conservation of wildlife of 0.651 is in an adequate state of conservation, but with a high vulnerability to pass to an acceptable state.

Table 5. Assignment of weights for each of the variables, through the software

\begin{tabular}{ccc}
\multicolumn{3}{c}{ (statistical analysis system 8.0) } \\
\hline Variable & Communal Method & $\%$ \\
\hline OD & 0.330 & 0.110 \\
pH_A & 0.570 & 0.189 \\
TB & 0.084 & 0.028 \\
Tm & 0.226 & 0.075 \\
CE & 0.437 & 0.145 \\
NNO3 & 0.084 & 0.028 \\
NNO2 & 0.293 & 0.097 \\
Phosphates & 0.563 & 0.187 \\
Total phosphorus & 0.423 & 0.141 \\
Sum & 3.010 & 1.000 \\
\hline
\end{tabular}

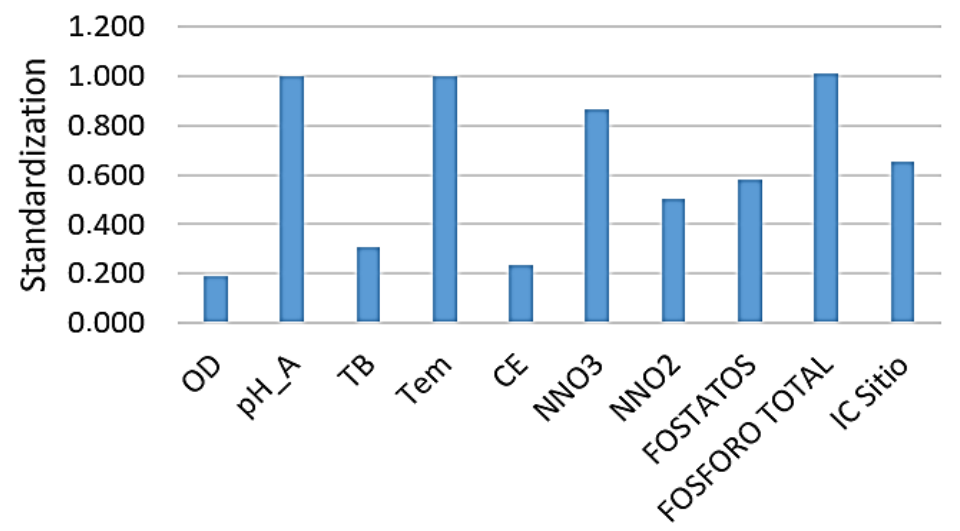

\section{Measured indicators}

Figure 2. Standardization and determination of the indices for each of the variables to obtain the total index 
Table 6. Parameterization of results

\begin{tabular}{ll}
\hline Sci Value & Characteristic \\
\hline $0.00-0.40$ & Critical state. The wetland is subject to stress that prevents compliance with its ecological functions. \\
$0.41-0.60$ & $\begin{array}{l}\text { Acceptable status. The wetland is within the limits of operation, but there are disturbances that diminish its self- } \\
\text { regulating capacity. }\end{array}$ \\
$0.61-0.80$ & $\begin{array}{l}\text { Appropriate state. The wetland complies with most of its ecological functions. } \\
0.81-1.00\end{array}$ \\
\hline
\end{tabular}

\section{DISCUSSION}

Wetlands are constantly subject to human pressures, related to productive systems and unsustainable use of the ecosystem, which has been reflected in a loss of water mirrors and a decrease in quality both for the conservation of aquatic life and for the provision of the different ecosystem services related to supply. Wetlands have been studied over time, authors such as [22] have conducted different research around quality indices in wetlands, especially highlighted for the purposes of this article, indexes for lentic systems which correspond to the type of wetland studied. This type of index has been developed according to [23] for several decades, especially those related to physical-chemical variables, where organic nitrogen, total phosphorus and dissolved oxygen have been specially analyzed, variables that were decisive when analyzing the Sonso Lagoon in Colombia. Yepez and Perez [24] developed a wetland conservation status index, which took into account parameters of biodiversity, fragmentation, soil and water in order to determine an integrated analysis of the ecosystem, Likewise, in this study, dissolved oxygen, temperature, $\mathrm{pH}$ and turbidity were taken into account in relation to water variables, where direct relationships between water and soil parameters were found, such as the case of the relationship between dissolved oxygen in water and phosphorus in the soil (the higher the phosphorus in the soil, the lower the dissolved oxygen in the water). In the case of the Sonso Lagoon in Colombia, different parameters were not considered, however, a greater number of physical-chemical water variables were considered to determine the status of biodiversity conservation in the lagoon [9], propose that temperature and dissolved oxygen are determining factors for vital processes of organisms, an aspect that was considered in the study of the Sonso Lagoon, and this is also considered in decree 1594 of 1984, where optimal levels of dissolved oxygen are mentioned for conservation purposes. From the literature analyzed, the wetlands present different states of conservation, from acceptable states to optimal states of conservation, however, those that are influenced by anthropic pressures represented in urbanism, neighboring productive systems and bad management practices, have accelerated deterioration trends and approaches to critical states, especially those located in urban areas that have a direct use and become undesirable spaces for the establishment of new infrastructure that seeks development regardless of the loss of ecosystems. The contamination of natural wetlands generates adverse effects on their ecology. This includes decreased dissolved oxygen (DO), high COD, and high nutrient content which in turn is related to eutrophication [25]. Eutrophication of lakes and ponds consists of the presence of nutrients in high quantities, mainly phosphorus. It is due to the increase in population and the intensification of land use. Livestock and agricultural activities in surrounding areas generate surface runoff into the lake or pond, with high concentrations of nutrients [26]-[28]. The main consequences of eutrophication are increased presence of algae, death of fish and excessive plant production [26]-[28].

In eutrophication processes, phosphorus seems to be the most important limiting factor for biological processes taking place in water bodies [26]. Phosphorus entering the lake tends to accumulate in sediments and biota. In addition, phosphorus is adsorbed onto suspended material, in greater quantity than nitrogen. Part of the phosphorus in the sediments returns to the water table, contributing to eutrophication [26], [28]. Conductivity is related to the concentration of ionized dissolved substances in the water and serves as an estimate of dissolved solids. The concentration of phosphates is a dissolved form of phosphorus [29].

\section{CONCLUSION}

The Sonso Lagoon is in a state suitable for the conservation of aquatic biodiversity, however, it is at the limit of an acceptable state, that is, it is a vulnerable wetland that requires special attention from environmental authorities. Dissolved oxygen is one of the most representative variables for analyzing the state of the wetlands according to this study and the others consulted, however, in this case total phosphorus, $\mathrm{pH}$ and temperature, the latter being directly related. The variables that obtained the greatest weight were phosphates, $\mathrm{pH}$, electrical conductivity and dissolved oxygen, which according to the literature are decisive for the conservation of biodiversity in water. At a general level, conservation indices show different behavior and the processes of anthropization are decisive for the quality of the wetlands, the greater the sedimentation, the greater the quantity of phosphates and therefore the greater the eutrophication. It was possible to obtain an index of the state of conservation of the Sonso Lagoon, from the multivariate analysis of the values of 13 main variables, recorded during a time window of 2004 to 2018, which had a calculated value of 0.65 , which 
allows us to conclude that the Lagoon is in an adequate state for the conservation of aquatic biodiversity, however, at the limit of an acceptable state, that is, it is a vulnerable wetland that requires special attention from the environmental authorities. On the other hand, of the 13 variables analyzed, those that presented the greatest weight were. On the other hand, the calculated value of the conservation index.

\section{ACKNOWLEDGMENTS}

The authors thank Universidad Católica de Manizales and Corporación Autónoma Regional del Valle del Cauca for the data provided.

\section{REFERENCES}

[1] R. E. De Walt, D. W. Webb, and M. A. Harris, "Summer ephemeroptera, plecoptera, and trichoptera (EPT) species richness and community structure in the lower illinois river basin of illinois," The Great Lakes Entomologist, vol. 32, no. 3, pp. 115-132, 1999.

[2] M. T. Barbour, "Rapid bioassessment protocols for use in wadeable streams and rivers: Periphyton, benthic macroinvertebrates and fish," US Environmental Protection Agency, Office of Water, 1999.

[3] H. A. Mohammed and S. F. Ismail, "Design and implementation of remotely monitoring system for pH level in Baghdad drinking water networks," TELKOMNIKA Telecommunication Computing Electronics and Control, vol. 19, no. 3, pp. 1030-1038, 2021, doi: 10.12928/TELKOMNIKA.v19i3.12921.

[4] C. M. Finlayson and N. R. Rea, "Reasons for the loss and degradation of Australian wetlands," Wetlands Ecology and Management, vol. 7, pp. 1-11, 1999, doi: 10.1023/A:1008495619951.

[5] V. H. Céspedes, G. Y. Florez, and Y. A. G. Gómez, "The internet of things in high andean wetland monitoring," Bulletin of Electrical Engineering and Informatics (BEEI), vol. 10, no. 3, pp. 1572-1579, 2021, doi: 10.11591/eei.v10i3.2653.

[6] T. M. Walski and F. L. Parker, "Consumers water quality index," Journal of the Environenment Engineering Divison, vol. 10, no. 3, 1974

[7] S. N. Ibrahim, A. L. Asnawi, N. A. Malik, N. F. M. Azmin, A. Z. Jusoh, and F. N. M. Isa, "Web based water turbidity monitoring and automated filtration system: IoT application in water management," International Journal of Electrical and Computer Engineering (IJECE), vol. 8, no. 4, pp. 2503-2511, 2018, doi: 10.11591/ijece.v8i4.pp2503-2511.

[8] N. E. Samboni Ruiz, Y. C. Escobar, and J. C. Escobar, "A review of physical-chemical parameters as water quality and contamination indicators," Ingeniería e Investigación, vol. 27, pp. 172-181, 2007, doi: 10.15446/ing.investig.

[9] C. Betancourt, R. Suarez, and L. Toledo, "Temporal distribution patterns of some physical and chemical variables in the paso bonito reservoir," Limnetica, vol. 28, no. 1, pp. 23-33, 2009.

[10] Z. M. Yusof, M. M. Billah, and K. Kadir, "Real-time water quality monitoring system: an IoT application," Indonesian Journal of Electrical Engineering and Computer Science (IJEECS), vol. 15, no. 1, pp. 178-182, 2019, doi: 10.11591/ijeecs.v15.i1.pp178182.

[11] X. Lin, S. Eguchi, S. Maeda, K. Yoshida, and H. Kuroda, "Combined effects of oxygen and temperature on nitrogen removal in a nitrate-rich ex-paddy wetland," Science of The Total Environment, vol. 779, pp. 146254, Jul. 2021, doi: 10.1016/j.scitotenv.2021.146254.

[12] J. Li et al., "Distinct roles of $\mathrm{pH}$ and organic ligands in the dissolution of goethite by cysteine," Journal of Environmental Sciences, vol. 113, pp. 260-268, Mar. 2022, doi: 10.1016/j.jes.2021.06.011.

[13] J. R. Zamora, "Physicochemical parameters of total hardness in calcium and magnesium, pH, conductivity and temperature of drinking water analyzed in conjunction with the aqueduct administrators associations (ASADAS)," (in Spanish) Pensamiento Actual, vol. 9, no. 12-13, pp. 125-134, 2009.

[14] A. G. P. Castillo and A. Rodríguez, "Physicochemical water quality index, a management tool for tropical-flooding lagoons," Revista de Biologia Tropical, vol. 56, no. 1, 2008, doi: 10.15517/rbt.v56i4.5769.

[15] E. Velasquez, P. Lavelle, and M. Andrade, "GISQ, a multifunctional indicator of soil quality," Soil Biology and Biochemistry, vol. 39, pp. 3066-3080, 2007, doi: 10.1016/j.soilbio.2007.06.013.

[16] G. P. Agudelo, J. D. Coy, and L. V. Mora, "Limnological state index (LSI) to evaluate ecological conditions of the canal del dique wetlands, Colombia," Acta Biologica Colombiana, vol. 15, no. 2, pp. 169-188, 2010.

[17] H. Sjors and U. Gunnarsson, "Calcium and pH in north and central Swedish mire waters," Journal of Ecology, vol. 90, no. 4, pp. 650-657, 2002, doi: 10.1046/j.1365-2745.2002.00701.x.

[18] L. A. Q. Rendón, E. A. Agudelo, Y. A. Q. Hernández, S. A. C. Gallo, and A. F. O. Arias, "Definition of indicators for marine and coastal water, sediments and soil quality in colombian ports," Gestión y Ambiente, vol. 13, pp. 51-64, 2010, doi: 10.15446/ga.

[19] E. R. Lecca, and E. C. R. Lizama, "Characterization of wastewater and biochemical oxygen demand," Industiral Data. vol. 17, 2014, doi: 10.15381/idata.v17i1.12035

[20] H. Wang et al., "Characterizing nitrate radical budget trends in Beijing during 2013-2019," Science of The Total Environment, vol. 795, Nov. 2021, Art. no. 148869, doi: 10.1016/j.scitotenv.2021.148869.

[21] X. Wang et al., "Effect of simulated tidal cycle on DOM, nitrogen and phosphorus release from sediment in Dagu River-Jiaozhou Bay estuary," Science of The Total Environment, vol. 783, pp. 147158, Aug. 2021, doi: 10.1016/j.scitotenv.2021.147158.

[22] G. A. P. Agudelo, "Experiences in the use of limnological indices in Colombia," Acta Biológica Colombiana, vol. 21 , no. 1, pp. 241-248, 2016, doi: 10.15446/abc.v21n1Supl.51073.

[23] R. E. Carlson, "A trophic state index for lakes1," Limnology and Oceanography, vol. 22, pp. 361-369, 1977, doi: 10.4319/1o.1977.22.2.0361.

[24] G. Y. F. Yepes and J. F. B. Pérez, "State of conservation index for high andean wetlands," Journal for Nature Conservation, vol. 49, pp. 45-53, 2019, doi: 10.1016/j.jnc.2019.02.004.

[25] W. Chen, J. Zheng, Z. Li, G. Shen, and Y. Li, "Status of water environment pollution in the Xixi Wetland and its ecological treatment countermeasures," Frontiers of Biology in China, vol. 4, pp. 228-232, 2009, doi: 10.1007/s11515-009-0004-y.

[26] G. E. Dumitran, L. I. Vuta, V. F. Piraianu, and C. Dragoi, "A mathematical model of a shallow and eutrophic lake (Stiucii Romania)," Energy Procedia, vol. 112, pp. 92-99, 2017, doi: 10.1016/j.egypro.2017.03.1068. 
[27] P. Singh, J. Bagrania, and A. K. Haritash, "Seasonal behaviour of thermal stratification and trophic status in a sub-tropical Palustrine water body," Applied Water Science, vol. 9, 2019, doi: 10.1007/s13201-019-1011-z.

[28] S. R. Carpenter, "Eutrophication of aquatic ecosystems: bistability and soil phosphorus," Proceedings of the National Academy of Sciences of the United States of America, vol. 102, no. 29, 2015, pp. 10002-10005, doi: 10.1073/pnas.0503959102.

[29] J. A. R. Rojas, Water quality, 3rd Ed., Escuela Colombiana de Ingeniería, Bogotá, 2009.

\section{BIOGRAPHIES OF AUTHORS}
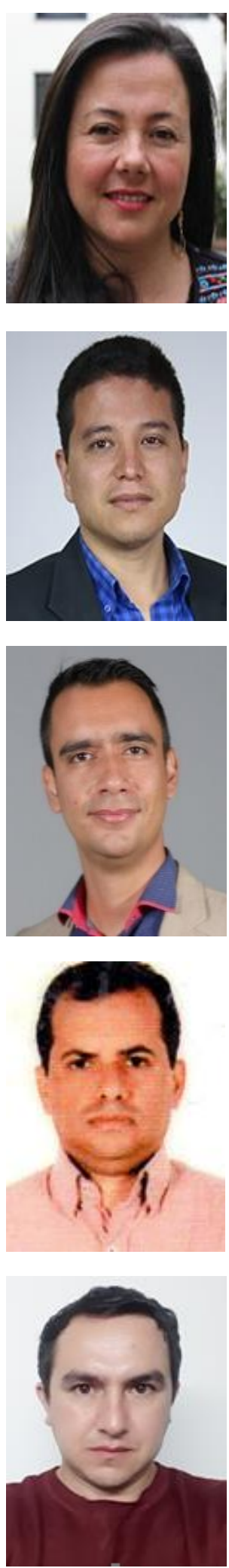

Gloria Yaneth Florez Yepes (D) $8 \mathrm{SC}$ P is B.Sc. in Environmental Administrator, M.Sc. Sustainable Development and the Environment, Ph.D. Sustainable Development. Professor at the Universidad Católica de Manizales Colombia, coordinator in the research group on Technological and Environmental Development. She can be contacted at email: gyflorez@ucm.edu.co.

Alejandro Rincón Santamaría (iD) $8 \mathrm{SC}$ P received the B.S. degree in Chemical Engineering, the M.S. degree in Engineering-Industrial Automation, and the Ph.D. degree in Engineering-Automation, from Universidad Nacional de Colombia at Manizales, Colombia, in 2006, 2007 and 2010, respectively. He is an associate professor with the Faculty of Engineering and Architecture, Universidad Católica de Manizales, Colombia. His research interests include: adaptive control design, robust control design, and bifurcation analysis. He can be contacted at email: arincons@ucm.edu.co.

Vladimir Henao Céspedes (iD) $\mathrm{SC}$ P received the B.S. degree in electronic engineering, the M.Sc. degree and the Ph.D. on engineering from Universidad Nacional de Colombia, Manizales. He currently an Associate Professor in the UAFCNM, at the Universidad Católica de Manizales, Manizales. His research interests include internet of things, electromagnetic compatibility, electromagnetic pollution, and lightning discharges. He is member of the Research Group on Tecnhonological and Environmental Development GIDTA. He can be contacted at email: vhenao@ucm.edu.co.

Juan Carlos Granobles (D) 8d SC P Agricultural Engineer. Specialist in Agricultural Management, Master in Farming Systems, degrees from the University of Caldas. Ph.D. student in Sustainable Development at the University of Manizales. He is a Research Professor at the University of Manizales. His research interests include: Sustainable farming systems. Modeling and simulation of farming systems, hydrographic basins and wetlands. Environmental impact studies. $\mathrm{He}$ can be contacted at email: jcgranobles@umanizales.edu.co.

Fredy Edimer Hoyos (D) S SC P from La Cruz, Nariño, Colombia, received his B.S. and M.S. degree from the National University of Colombia, at Manizales, Colombia, in Electrical Engineering and Industrial Automation, in 2006 and 2009, respectively, and his $\mathrm{Ph} . \mathrm{D}$. in Engineering with an emphasis in Automation in 2012. Dr. Hoyos is now an Assistant Professor of the Universidad Nacional de Colombia-Sede Medellín. His research interests include nonlinear control, system modelling, nonlinear dynamics analysis, control of nonsmooth systems, and power electronics, with application within a broad area of technological process. Dr. Hoyos is an Associate Researcher in Colciencias and member of the Applied Technologies Research Group-GITA at the Universidad Nacional de Colombia. He can be contacted at email: fehoyosve@unal.edu.co. 